\title{
CrystEngComm
}

\section{Stereoisomeric semiconducting radical cation salts of chiral bis(2-hydroxypropylthio)ethylenedithioTTF with tetrafluoroborate anions $\uparrow$}

Cite this: CrystEngComm, 2014, 16 5424

Received 16th January 2014, Accepted 29th April 2014

DOI: $10.1039 / c 4 c e 00116 h$

www.rsc.org/crystengcomm

\author{
Lee Martin, ${ }^{* a}$ John D. Wallis, ${ }^{a}$ Milena A. Guziak, ${ }^{\text {ab }}$ Jack Oxspring, ${ }^{a}$ Jordan R. Lopez, ${ }^{a}$ \\ Shin'ichi Nakatsuji, ${ }^{\mathrm{C}}$ Jun'ichi Yamada ${ }^{\mathrm{C}}$ and Hiroki Akutsu ${ }^{\mathrm{C}}$
}

\begin{abstract}
The new chiral TTF-based donor molecule bis(2-hydroxypropylthio)ethylenedithiotetrathiafulvalene has produced enantiopure $R, R$ and $S, S$ radical cation salts with the tetrafluoroborate anion as well as the nearly isostructural meso/racemate mixture. The enantiopure $R, R$ or $S, S$ salts are both $1: 1$ semiconducting salts with activation energies of $0.19-0.24 \mathrm{eV}$, both crystallising in the orthorhombic space group C222 1 . The semiconducting salt containing both meso and racemic donor cations has a very similar crystal structure but crystallising in the monoclinic space group $C 2 / c\left(\beta=91.39^{\circ}\right)$ with similar $\mathrm{S} \cdots \mathrm{S}$ interactions but a smaller activation energy of $0.15-0.17 \mathrm{eV}$. This is in contrast to previous families of this type where the disordered racemate has a larger activation energy than its enantiopure salts.
\end{abstract}

\section{Introduction}

The organosulphur donors TTF (2) and BEDT-TTF (3) have produced a large number of radical cation salts combining a variety of electrical properties. ${ }^{1}$ The TTF based molecular conductors provide an excellent opportunity to explore the combination of chirality and conductivity in the same crystal lattice which is of importance in understanding magnetochiral anisotropy as seen in carbon nanotubes. ${ }^{2}$ In order to explore the effect of handedness on a conducting material a number of approaches have been taken to introduce chirality into TTF based conductors. Chiral radical cation salts have included a variety of chiral anions, chiral donors, or have been electrocrystallised from a chiral solvent. ${ }^{3}$ Differences in the conductivities have been observed between the racemic and enantiopure forms owing to structural disorder in the former. Radical cation salts have previously been synthesized from a variety of chiral anions including $\left[\mathrm{Sb}_{2}(\mathrm{~L}-\text { tartrate })_{2}\right]^{2-}$, $\left[\mathrm{Fe}(\text { croconate })_{3}\right]^{3-}, \quad\left[\mathrm{Cr}\left(2,2^{\prime} \text {-bipy }\right)(\text { oxalate })_{2}\right]^{-}, \quad$ TRISPHAT, D-camphorsulfonate, and $\mathrm{Co}^{\mathrm{III}}$ complexes of optically pure pyridinecarboxamide anions. There is an extensive

\footnotetext{
${ }^{a}$ School of Science and Technology, Nottingham Trent University, Clifton Lane, Nottingham, NG11 8NS, UK. E-mail: lee.martin@ntu.ac.uk

${ }^{b}$ Low Temperature Condensed State Physics, Institute for Material Research, Tohoku University, Katahira 2-1-1, Sendai 980-8577, Japan

${ }^{c}$ Graduate School of Material Science, University of Hyogo, Kamigori-cho, Ako-gun, Hyogo, 678-1297, Japan

$\dagger$ CCDC 981724-981726. For crystallographic data in CIF or other electronic format see DOI: 10.1039/c4ce00116h
}

family of metal trisoxalate salts of the formula BEDT-TTF $4\left[\left(\mathrm{NH}_{4} / \mathrm{H}_{3} \mathrm{O}\right) \mathrm{M}(\text { oxalate })_{3}\right]$.guest in which the distribution of the $\Delta$ and $\Lambda$ enantiomers of $\mathrm{M}$ (oxalate) ${ }_{3}{ }^{3-}(\mathrm{M}=\mathrm{Fe}$, $\mathrm{Cr}, \mathrm{Co}, \mathrm{Al}, \mathrm{Ga}$ ) leads to different polymorphs exhibiting either superconducting or semiconducting behaviour. ${ }^{4}$ The guest molecules included in the anion layer can lead to different donor packing motifs and thus different conducting properties. When either racemic $(R / S)$ - or enantiopure (S)-sec-phenethyl alcohol is included as a guest molecule isostructural salts are obtained. A more pronounced metal-insulator transition is observed for the racemate owing to the enantiomeric disorder in the $R / S$ salt. Crystallisation from chiral solvents has also led to salts of the form (BEDT-TTF $)_{3}\left[\mathrm{NaCr}(\text { oxalate })_{3}\right]$.guest which contain a single enantiomer of the $\mathrm{Cr}(\text { oxalate })_{3}$ anion through chiral induction. ${ }^{5}$ Dunitz et al. synthesized the first enantiopure TTF-based donor molecule with $(S, S, S, S)$-tetramethyl-BEDT-TTF $(4) .{ }^{6}$ In recent years there has been increased interest in the synthesis of chiral donor molecules, of particular note being the selective transformation of a TTF sulphur atom to its sulfoxide giving a chiral sulfur (5), ${ }^{7}$ TTF-oxazolines $(6),{ }^{8}$ bis(pyrrolo)TTF $(7),{ }^{9}$ and pinene-BEDT-TTF (8) (Scheme 2). ${ }^{10}$ Effects of structural disorder on conducting properties have also been evidenced in salts of TTF-oxazolines. ${ }^{8 d, e, 11}$

We have recently reported the synthesis of the novel enantiopure donor molecule bis((2S)-2-hydroxypropylthio)ethylenedithio-tetrathiafulvalene 1 which has both chirality and the potential to form hydrogen bonds in its 2-hydroxypropylthio sidechains (Scheme 1). We previously reported the first examples of radical cation salts from this enantiopure $S, S$-donor molecule including one with the 


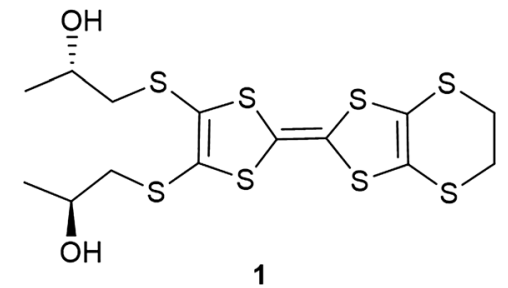

Scheme 1

meso stereoisomer of the $\mathrm{Fe}_{2}$ (oxalate) $)_{5}{ }^{4-}$ anion. ${ }^{12}$ Following the method reported previously for the $S, S$-donor of 1 we have synthesised the $R, R$ enantiomer and also a statistical mixture of the meso/racemate forms $(1: 1: 2 R, R: S, S: R, S)$, the latter being prepared by using racemic methyl-oxirane as a starting material.

Through electrocrystallisation with the anion $\mathrm{BF}_{4}{ }^{-}$ we have synthesised the first family of radical cation salts from enantiopure $R, R-1, S, S-1$ and meso/rac-1. All three materials are semiconducting, and it is of interest that the two enantiopure stereoisomers have similar activation energies whilst the almost isostructural meso/racemate has a smaller activation energy and a slightly higher room temperature conductivity. This is opposite to what was observed previously in TTF-oxazoline-PF ${ }_{6}$, TM-BEDT-TTF- ${ }_{3}{ }^{6 e}$ and BEDT$\mathrm{TTF}_{4}\left[\left(\mathrm{NH}_{4}\right) \mathrm{Fe}(\text { oxalate })_{3}\right] \cdot$ sec-phenethyl alcohol ${ }^{5}$ where the structural disorder had the effect of reducing the conductivity. Attempts to produce crystals from a 50:50 mixture of enantiopure $R R-\mathbf{1}: S S-\mathbf{1}$ donor mixture did not produce crystals suitable for X-ray or resistivity measurement.

\section{Experimental}

Enantiopure donor $R, R-\mathbf{1}$ and the mixture of racemic and meso forms of 1 were synthesized using the method described previously for $S, S-\mathbf{1}$ starting from the $R^{-}$or rac-methyloxirane respectively. ${ }^{12}$ At no stage in the syntheses could the racemic and meso isomers be separated. Single crystals of $(S, S)-\mathbf{1} \cdot \mathbf{B F}_{4},(R, R)-\mathbf{1} \cdot \mathbf{B F}_{4}$, and meso/rac-1. $\mathbf{B F}_{4}$ were grown by electrocrystallisation using donor $(S, S)-\mathbf{1},(R, R)-\mathbf{1}$, and the $m e s o /$ racemic mixture of 1 , respectively, as follows:

$100 \mathrm{mg}$ of tetrabutylammonium tetrafluoroborate was dissolved in $20 \mathrm{ml}$ of chlorobenzene and then added to the cathode side of a $\mathrm{H}$-shaped cell. $10 \mathrm{mg}$ of donor 1 was dissolved in $20 \mathrm{ml}$ of chlorobenzene and added to the anode side of the $\mathrm{H}$-shaped cell. Chlorobenzene and tetrabutylammonium tetrafluoroborate were purchased from Aldrich and used as received.

The H-shaped cells had two platinum electrodes separated by a porous glass frit to prevent contamination. The electrodes were cleaned by applying a voltage across the electrodes in $1 \mathrm{M}$ $\mathrm{H}_{2} \mathrm{SO}_{4}$ in each direction resulting in the evolution of $\mathrm{H}_{2}$ and $\mathrm{O}_{2}$ at the electrodes. Finally the electrodes were washed in distilled water and thoroughly dried. The cells were fixed inside sandfilled compartments on a vibration-free table and kept at a constant temperature of $293 \mathrm{~K}$.

A current of $0.1 \mu \mathrm{A}$ was passed through the platinum electrodes and black needle crystals of the $\mathbf{1} \cdot \mathbf{B F}_{\mathbf{4}}{ }^{-}$radical cation salts grew on the anode over 3 weeks.

Four-probe DC transport measurements were made on several crystals of $(S, S)-\mathbf{1} \cdot \mathbf{B F}_{4},(R, R)-\mathbf{1} \cdot \mathbf{B F}_{4}$, and meso/rac-1. $\mathbf{B F}_{4}$ using a HUSO HECS 994C multi-channel conductometer. Gold wires (15 $\mu \mathrm{m}$ diameter) were attached to the crystal, and the attached wires were connected to an four-pin integrated circuit plug with gold conductive cement.

\section{Results and discussion}

Both $(S, S)-\mathbf{1} \cdot \mathbf{B F}_{\mathbf{4}}$ and $(R, R)-\mathbf{1} \cdot \mathbf{B F}_{\mathbf{4}}$ crystallise in the orthorhombic system in chiral space group $C 222_{1}$ (Fig. 1), whilst<smiles>C1=CSC(=C2SC=CS2)S1</smiles>

2<smiles>C1CSC2=C(S1)SC(=C1SC3=C(SCCS3)S1)S2</smiles>

3<smiles>C[C@H]1SC2=C(SC(=C3SC4=C(S3)S[C@H](C)[C@@H](C)S4)S2)S[C@@H]1C</smiles>

4<smiles>[O][Se]1C2=C(SCCS2)SC1=C1SC2=C(SCCS2)S1</smiles>

5<smiles>C[C@H](c1ccccc1)n1cc2c(c1)SC(=C1Sc3cn([C@H](C)c4ccccc4)cc3S1)S2</smiles><smiles>C[C@H]1COC(C2=CSC(=C3SC4=C(SCCS4)S3)S2)=N1</smiles>

6 


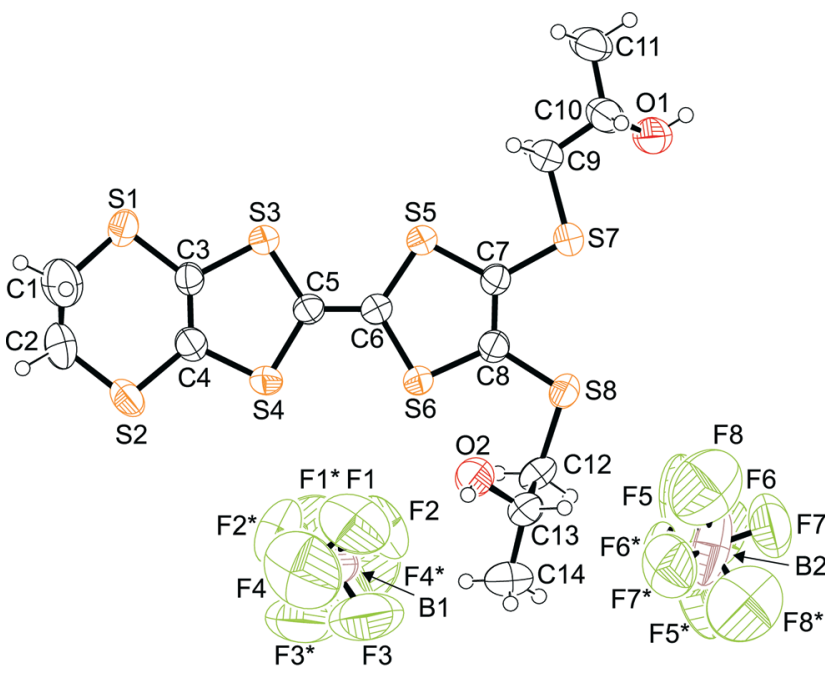

(a)

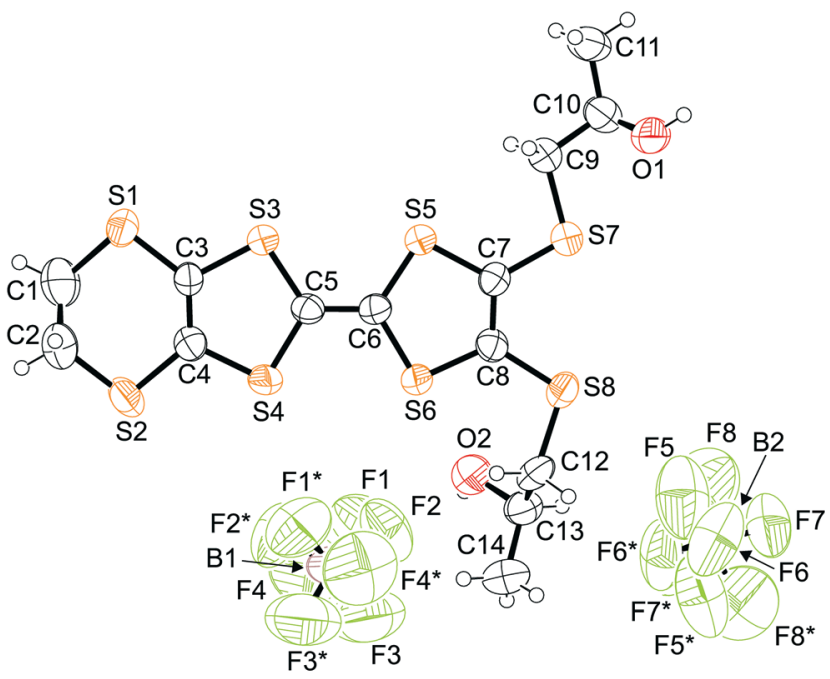

(b)

Fig. 1 ORTEP image of (a) $(S, S)-1 \cdot \mathrm{BF}_{4}$ and (b) $(R, R)-1 \cdot \mathrm{BF}_{4}$.

meso/rac-1 $\cdot \mathbf{B F}_{4}$ crystallises in monoclinic $C 2 / c$ (Fig. 2) (Table 1). The crystals of all three salts have one donor molecule and two crystallographically independent $\mathrm{BF}_{4}{ }^{-}$anions, but both anions lie on symmetry elements, a 2-fold axis for the enantiomers and a centre of symmetry for the meso/racemate. For the enantiopure salts the $\mathrm{BF}_{4}$ anions are disordered and for the meso/rac-salt they are placed on centres of symmetry of the $C 2 / c$ space group, and thus must appear disordered.

In all three salts the donor molecules form stacks in the $a$ direction (Fig. 3-5) with neighbouring stacks segregated in the $b$ direction by $\mathrm{BF}_{4}{ }^{-}$anions. In the enantiopure salts, the best planes of donor cations lie at $c a .68^{\circ}$ to the stacking axis. Pairs of donors, related by a 2 -fold axis, are dimerised face-to-face with short $S \cdots S$ contacts between the four central TTF sulfur atoms as shown in Fig. 5. S $\cdots S$ contacts are similar in both enantiopure and rac/meso salts (Table 2). The plane-plane distance between donors in all three salts are

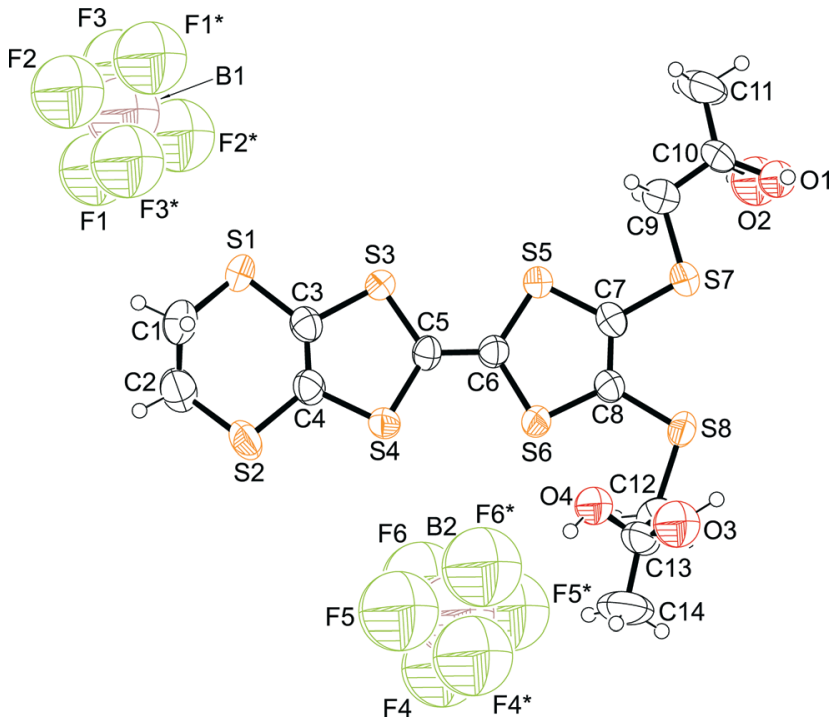

Fig. 2 ORTEP image of meso/rac-1·BF

Table 1 Crystallographic data for $\mathrm{BF}_{4}$ salts of $1^{a}$

\begin{tabular}{|c|c|c|c|}
\hline & meso/rac-1. $\cdot \mathbf{B F}_{4}$ & $(S, S)-\mathbf{1} \cdot \mathbf{B F}_{\mathbf{4}}$ & $(R, R)-\mathbf{1} \cdot \mathbf{B F}_{\mathbf{4}}$ \\
\hline Formula & $\mathrm{C}_{14} \mathrm{H}_{18} \mathrm{O}_{2} \mathrm{~S}_{8} \cdot \mathrm{BF}_{4}$ & $\mathrm{C}_{14} \mathrm{H}_{18} \mathrm{O}_{2} \mathrm{~S}_{8} \cdot \mathrm{BF}_{4}$ & $\mathrm{C}_{14} \mathrm{H}_{18} \mathrm{O}_{2} \mathrm{~S}_{8} \cdot \mathrm{BF}_{4}$ \\
\hline$M_{\mathrm{r}} / \mathrm{g} \mathrm{mol}^{-1}$ & 561.58 & 561.58 & 561.58 \\
\hline Temp/K & 300.1 & 293.1 & 293.1 \\
\hline$\mu / \mathrm{cm}^{-1}$ & 8.416 & 8.416 & 8.401 \\
\hline Crystal system & Monoclinic & Orthorhombic & Orthorhombic \\
\hline Space group & $C 2 / c$ & $C 222_{1}$ & $C 222_{1}$ \\
\hline$a / \AA$ & $7.807(3)$ & $7.8100(13)$ & $7.8172(13)$ \\
\hline$b / \AA$ & $21.223(6)$ & $21.238(4)$ & $21.232(4)$ \\
\hline$c / \AA ̊ \AA$ & $26.992(7)$ & 26.989(5) & $26.987(5)$ \\
\hline$\alpha /^{\circ}$ & 90 & 90 & 90 \\
\hline$\beta /{ }^{\circ}$ & $91.394(7)$ & 90 & 90 \\
\hline$\gamma /{ }^{\circ}$ & 90 & 90 & 90 \\
\hline$V / \AA^{3}$ & 4471(3) & $4476.6(13)$ & 4479.1(13) \\
\hline$Z$ & 8 & 8 & 8 \\
\hline$\rho / \mathrm{g} \mathrm{cm}^{-3}$ & 1.669 & 1.666 & 1.665 \\
\hline Flack parameter & & $-0.08(15)$ & $-0.03(17)$ \\
\hline$R_{1}[I>2 \sigma(I)]$ & 0.106 & 0.0486 & 0.0603 \\
\hline $\mathrm{w} R$ [all data] & 0.335 & 0.123 & 0.142 \\
\hline CCDC no. & 981724 & 981726 & 981725 \\
\hline
\end{tabular}

${ }^{a} \mathrm{X}$-ray single crystal diffraction measurements were performed by a Rigaku Mercury 2 CCD configured with Rigaku MicroMax-007HF generator and VariMax confocal mirror using MoK $\alpha$ radiation $(\lambda=0.71073 \AA)$. Structures were solved by direct methods (SIR2004, SIR2008 and SIR92 for meso/rac-, $(S, S)$ - and $(R, R)$-salts, respectively and refined by full-matrix least squared techniques based on $F^{2}$ (SHELX97). Non-hydrogen atoms were refined with anisotropic displacement parameters apart from $\mathrm{BF}_{4}$ anions of meso/rac-salt, which were refined with isotropic displacement parameters.

similar: ca. $3.37 \AA$ A within a pair, and ca. 3.77 A between pairs, despite the different crystal systems, and adjacent pairs are slipped by $c a$. $2.3 \AA$, while within a pair the slip distance is ca. $0.9 \AA$ (Table 3).

The central $\mathrm{C}=\mathrm{C}$ bond lengths in all cases are close to the value expected for a TTF donor charge of $1^{+}:(S, S)-\mathbf{1} \cdot \mathbf{B F}_{4}$ $1.400(5) \AA,(R, R)-1 \cdot B_{4} 1.398(6) \AA$, and meso/rac-1·BF 4 1.389(10) $\AA$. 


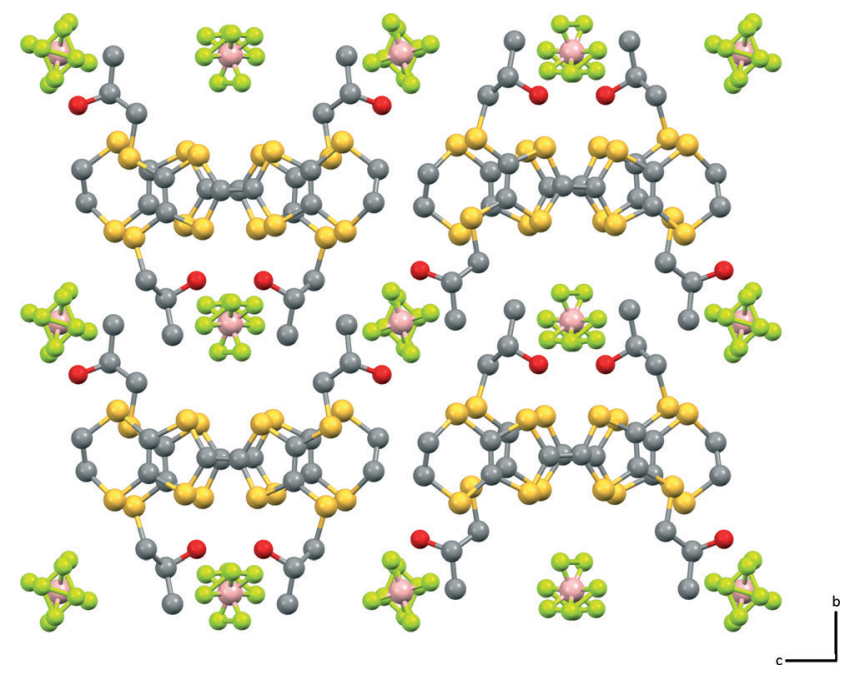

Fig. 3 Crystal structure of $(S, S)-1 \cdot B_{4}$ viewed down the a axis. Hydrogen atoms removed for clarity.

For the enantiopure salts the two hydroxylated side chains adopt different conformations, one lies in the donor plane

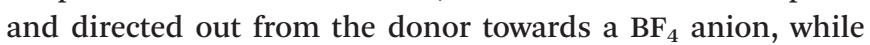
the other bends down under the donor. Dimer pairs are likely to be connected by hydrogen bonding, since two symmetry related oxygen atoms from the latter type of side chains lie 2.877(6) $\AA$ apart in the $R, R$ enantiomer (2.876(5) $\AA$ in the $S, S)$. It was not possible to detect hydroxyl hydrogen atom positions from the difference Fourier maps arising from the room temperature diffraction data for either enantiomer. There is a long $\mathrm{O} \cdots \mathrm{H}-\mathrm{C}$ contact from the other side chain to the ethylene bridge of a donor molecule (2.57 $R, R$-isomer). For the $\mathrm{rac} / \mathrm{meso}$ salt, the overall conformation of the donors is very similar to that in the enantiomeric salts, but there are two positions for each hydroxyl oxygen atom. For the side chain directed out from the donor, both $\mathrm{O}$ positions are directed towards $\mathrm{BF}_{4}$ anions (O $\left.\cdots \mathrm{F}: 2.671,2.922 \AA\right)$. For the other side chain, one oxygen position corresponds to those involved in a hydrogen bond between donor pairs, while the other is directed towards a $\mathrm{BF}_{4}$ anion $(\mathrm{O} \cdots \mathrm{F}: 2.671 \AA$ ) .

Four-probe transport measurements performed parallel to the longest axis of several needle-shaped crystals show

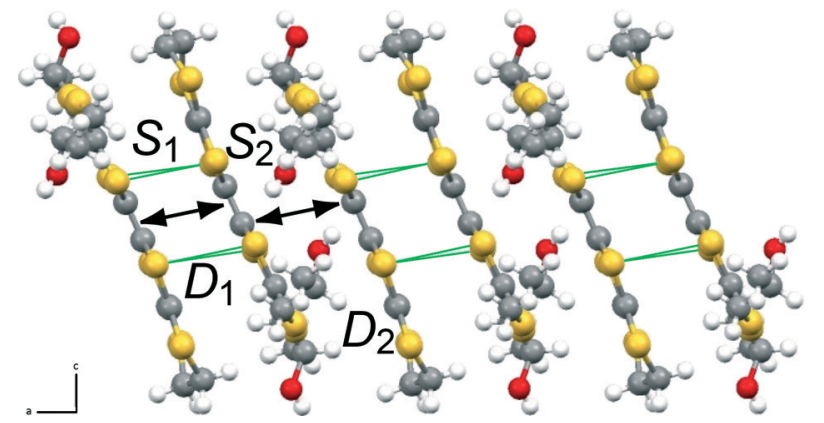

Fig. 5 Face-to-face packing of donors viewed down the $b$ axis showing close $\mathrm{S} \cdots \mathrm{S}$ contacts for $(\mathrm{S}, \mathrm{S})-1 \cdot \mathrm{BF}_{4} \cdot \mathrm{BF}_{4}$ anions have been removed for clarity.

Table 2 Short $\mathrm{S} \cdots \mathrm{S}$ contacts for $\mathrm{BF}_{4}$ salts of 1

\begin{tabular}{llll}
\hline & meso $/ \mathrm{rac}-\mathbf{1} \cdot \mathbf{B F}_{4}$ & $(S, S)-\mathbf{1} \cdot \mathbf{B F}_{4}$ & $(R, R)-\mathbf{1} \cdot \mathbf{B F}_{4}$ \\
\hline S3 $\cdots$ S5 & $3.560(4) \AA$ & $3.557(2) \AA$ & $3.562(2) \AA$ \\
S4 $\cdots$ S6 & $3.476(4) \AA$ & $3.466(2) \AA$ & $3.468(2) \AA$
\end{tabular}

Table 3 The plane-plane distance of $D_{1}$ and $D_{2}$ (see Fig. 5) and the corresponding slip distances of $S_{1}$ and $S_{2}$ (ref. 13)

\begin{tabular}{lllll}
\hline & $D_{1}$ & $D_{2}$ & $S_{1}$ & $S_{2}$ \\
\hline meso $/ \mathrm{rac}-\mathbf{1} \cdot \mathbf{B F}_{4}$ & $3.378 \AA$ & $3.658 \AA$ & $0.957 \AA$ & $2.343 \AA$ \\
$(S, S)-\mathbf{1} \cdot \mathbf{B F}_{4}$ & $3.368 \AA$ & $3.665 \AA$ & $0.974 \AA$ & $2.385 \AA$ \\
$(R, R)-\mathbf{1} \cdot \mathbf{B F}_{4}$ & $3.371 \AA$ & $3.665 \AA$ & $0.978 \AA$ & $2.391 \AA$
\end{tabular}

that $(S, S)-\mathbf{1} \cdot \mathbf{B F}_{\mathbf{4}},(R, R)-\mathbf{1} \cdot \mathbf{B F}_{\mathbf{4}}$, and meso/rac- $\mathbf{1} \cdot \mathbf{B F}_{\mathbf{4}}$ are all semiconducting (Fig. 6). Room temperature resitivities are similar but the activation energy for the racemate is significantly smaller than for either the $S, S$ or $R, R$ (Table 4). It has been observed recently in the case of DM-EDT-TTF-PF 6 that the racemic salt is metallic whilst the enantiopure salts are semiconducting due to the differences between the packing. ${ }^{14}$ However in the case of $\mathbf{1}$ although the enantiopure and meso/racemate have different crystal systems they are almost isostructural, differing slightly in the donor molecule slip distances (Fig. 5).

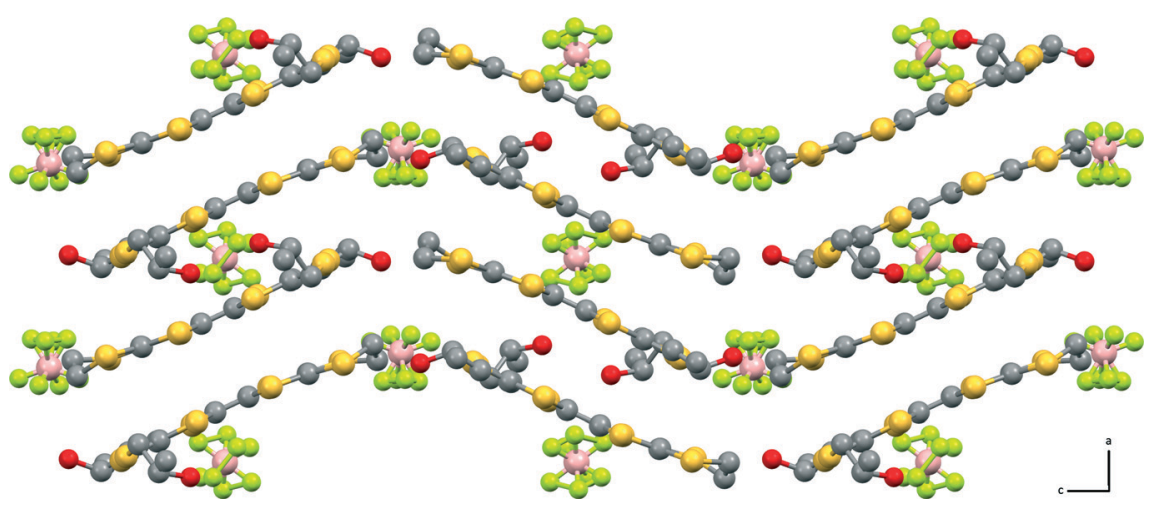

Fig. 4 Crystal structure of $(S, S)-1 \cdot \mathrm{BF}_{4}$ viewed down the $b$ axis. Hydrogen atoms removed for clarity. 


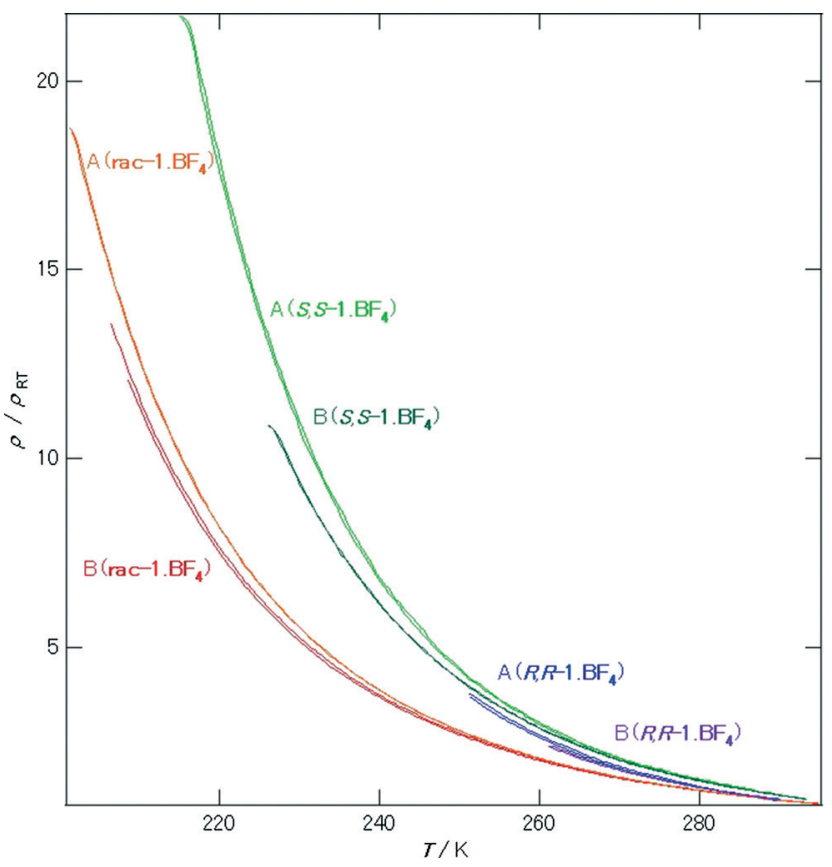

Fig. 6 Temperature dependence of electrical resistivity $\rho / \rho(\mathrm{RT})$ for two single crystals $(\mathrm{A}$ and $\mathrm{B})$ for each of $(S, S)-1 \cdot \mathrm{BF}_{4},(R, R)-1 \cdot \mathrm{BF}_{4}$, and meso/rac-1 $\cdot \mathrm{BF}_{4}$.

Table $4 E_{\mathrm{a}}$ and room temperature resistivity values for crystals of $(S, S)-1 \cdot \mathrm{BF}_{4},(R, R)-1 \cdot \mathrm{BF}_{4}$, and meso/rac-1. $\mathrm{BF}_{4}$

\begin{tabular}{lll}
\hline meso/rac $\mathbf{- 1} \cdot \mathbf{B F}_{\mathbf{4}}$ & $(S, S)-\mathbf{1} \cdot \mathbf{B F}_{\mathbf{4}}$ & $(R, R)-\mathbf{1} \cdot \mathbf{B F}_{4}$ \\
\hline $0.156 \mathrm{eV}$ & $0.218 \mathrm{eV}$ & $0.244 \mathrm{eV}$ \\
$1.6 \times 10^{3} \mathrm{Ohm} \mathrm{cm}$ & $1.3 \times 10^{3} \mathrm{Ohm} \mathrm{cm}$ & $2.9 \times 10^{4} \mathrm{Ohm} \mathrm{cm}$ \\
$0.167 \mathrm{eV}$ & $0.205 \mathrm{eV}$ & $0.202 \mathrm{eV}$ \\
$8.6 \times 10^{2} \mathrm{Ohm} \mathrm{cm}$ & $2.0 \times 10^{3} \mathrm{Ohm} \mathrm{cm}$ & $1.1 \times 10^{3} \mathrm{Ohm} \mathrm{cm}$
\end{tabular}

\section{Conclusions}

We report the first family of semiconducting salts of the enantiopure donor bis(2-hydroxypropylthio)ethylenedithiotetrathiafulvalene and observe a lower activation energy for the racemic analogue compared to both single enantiomers. This new donor molecule shows promise for the synthesis of many families of conducting chiral radical cation salts to investigate magnetochiral anisotropy. The hydrogen bonding ability of the 2-hydroxypropylthio side-chains with the multitude of anions available has the potential to produce a variety of novel TTF packing arrangements.

\section{Acknowledgements}

LM and SN would like to thank the Royal Society for an International Joint Project Grant (JP0869972) and a Royal Society Research Grant (RG100853). LM would also like to thank the Royal Society of Chemistry for a Journal Grant for International Authors. JDW would like to thank EPSRC for grant EP/C510488/1.

\section{Notes and references}

1 (a) E. Coronado, J. R. Galan-Mascaros, C. J. Gomez-Garcia and V. Laukhin, Nature, 2000, 408, 447; (b) A. Alberola, E. Coronado, J. R. Galan-Mascaros, C. Gimenez-Saiz and C. Gomez-Garcia, J. Am. Chem. Soc., 2003, 125, 10774; (c) A. Akutsu-Sato, H. Akutsu, S. S. Turner, P. Day, M. R. Probert, J. A. K. Howard, T. Akutagawa, S. Takeda, T. Nakamura and T. Mori, Angew. Chem., Int. Ed., 2005, 44, 292.

2 V. Krstić, S. Roth, M. Burghard, K. Kern and G. L. J. A. Rikken, J. Chem. Phys., 2002, 117, 11315.

3 N. Avarvari and J. D. Wallis, J. Mater. Chem., 2009, 19, 4061 .

4 (a) L. Martin, S. S. Turner, P. Day, K. M. Abdul Malik, S. J. Coles and M. B. Hursthouse, Chem. Commun., 1999, 513; (b) L. Martin, S. S. Turner, P. Day, P. Guionneau, J. K. Howard, D. E. Hibbs, M. E. Light, M. B. Hursthouse, M. Uruichi and K. Yakushi, Inorg. Chem., 2001, 40, 1363; (c) E. Coronado, J. R. Galán-Mascarós, C. J. Gómez-García, A. Murcia-Martinez and E. Canadell, Inorg. Chem., 2004, 43, 8072; (d) A. M. Madalan, E. Canadell, P. Auban-Senzier, D. Brânzea, N. Avarvari and M. Andruh, New J. Chem., 2008, 32, 333; (e) M. Clemente-León, E. Coronado, C. J. Gómez-García, A. Soriano-Portillo, S. Constant, R. Frantz and J. Lacour, Inorg. Chim. Acta, 2007, 360, 955; $(f)$ C. J. Gómez-García, E. Coronado, S. Curreli, C. Giménez-Saiz, P. Deplano, M. L. Mercuri, L. Pilia, A. Serpe, C. Faulmann and E. Canadell, Chem. Commun., 2006, 4931; (g) M. Brezgunova, K.-S. Shin, P. Auban-Senzier, O. Jeannin and M. Fourmigué, Chem. Commun., 2010, 46, 3926; (h) N. P. Chmel, L. E. N. Allana, J. M. Becker, G. J. Clarkson, S. S. Turner and P. Scott, Dalton Trans., 2011, 40, 1722.

5 (a) L. Martin, P. Day, H. Akutsu, J-I. Yamada, S.-I. Nakatsuji, W. Clegg, R. W. Harrington, P. N. Horton, M. B. Hursthouse, P. McMillan and S. Firth, CrystEngComm, 2007, 10, 865; (b) L. Martin, P. Day, S.-I. Nakatsuji, J.-I. Yamada, H. Akutsu and P. Horton, CrystEngComm, 2010, 12, 1369; (c) L. Martin, S.-I. Nakatsuji, J.-I. Yamada, H. Akutsu and P. Day, J. Mater. Chem., 2010, 20, 2738.

6 (a) J. D. Dunitz, A. Karrer and J. D. Wallis, Helv. Chim. Acta, 1986, 69, 69; (b) A. Karrer, J. D. Wallis, J. D. Dunitz, B. Hilti, C. W. Mayer, M. Burkle and J. Pfeiffer, Helv. Chim. Acta, 1987, 70, 942; (c) J. R. Galán-Mascarós, E. Coronado, P. A. Goddard, J. Singleton, A. I. Coldea, J. D. Wallis, S. J. Coles and A. Alberola, J. Am. Chem. Soc., 2010, 132, 9271; (d) F. Riobé, F. Piron, C. Réthoré, A. M. Madalan, C. J. Gómez-García, J. Lacour, J. D. Wallis and N. Avarvari, New J. Chem., 2009, 35, 2279; (e) F. Pop, S. Laroussi, T. Cauchy, C. J. Gómez-García, J. D. Wallis and N. Avarvari, Chirality, 2013, 25, 466.

7 (a) M. Chas, M. Lemarié, M. Gulea and N. Avarvari, Chem. Commun., 2008, 220; (b) M. Chas, F. Riobé, R. Sancho, C. Minguillón and N. Avarvari, Chirality, 2009, 21, 818.

8 (a) C. Réthoré, M. Fourmigué and N. Avarvari, Chem. Commun., 2004, 1384; (b) C. Réthoré, M. Fourmigué and 
N. Avarvari, Tetrahedron, 2005, 61, 10935; (c) C. Réthoré, A. Madalan, M. Fourmigué, E. Canadell, E. B. Lopes, M. Almeida, R. Clérac and N. Avarvari, New J. Chem., 2007, 31, 1468; (d) C. Réthoré, N. Avarvari, E. Canadell, P. Auban-Senzier and M. Fourmigué, J. Am. Chem. Soc., 2005, 127, 5748; (e) A. M. Madalan, C. Réthoré, M. Fourmigué, E. Canadell, E. B. Lopes, M. Almeida, P. Auban-Senzier and N. Avarvari, Chem. - Eur. J., 2010, 16, 528.

9 S. Yang, A. C. Brooks, L. Martin, P. Day, H. Li, L. Male, P. Horton and J. D. Wallis, CrystEngComm, 2009, 11, 993.
10 S. Yang, A. C. Brooks, L. Martin, P. Day, M. Pilkington, W. Clegg, R. W. Harrington, L. Russo and J. D. Wallis, Tetrahedron, 2010, 66, 6977.

11 N. Avarvari, Rev. Roum. Chim., 2009, 54(6), 411.

12 I. Awheda, S. Krivickas, S. Yang, L. Martin, M. A. Guziak, A. C. Brooks, F. Pelletier, M. Le Kerneau, P. Day, P. Horton, H. Akutsu and J. D. Wallis, Tetrahedron, 2013, 69, 8738.

13 T. Mori, Bull. Chem. Soc. Jpn., 1998, 71, 2509.

14 F. Pop, P. Auban-Senzier, A. Frąckowiak, K. Ptaszyński, I. Olejniczak, J. D. Wallis, E. Canadell and N. Avarvari, J. Am. Chem. Soc., 2013, 135, 17176. 